\title{
'Hass' Avocado Carbohydrate Fluctuations. II. Fruit Growth and Ripening
}

\author{
Xuan Liu, Paul W. Robinson, Monica A. Madore, Guy W. Witney, ${ }^{1}$ and Mary Lu Arpaia ${ }^{2}$ \\ Department of Botany and Plant Sciences, University of California, Riverside, CA 92521
}

\begin{abstract}
AdDitional INDEX words. 'Hass' avocado, 'Duke 7' rootstock, D-mannoheptulose, Persea americana, perseitol, soluble sugar, starch

Abstract. Changes in soluble sugar and starch reserves in avocado (Persea americana Mill. on 'Duke 7' rootstock) fruit were followed during growth and development and during low temperature storage and ripening. During the period of rapid fruit size expansion, soluble sugars accounted for most of the increase in fruit tissue biomass (peel: $17 \%$ to $22 \%$, flesh: $40 \%$ to $44 \%$, seed: $32 \%$ to $41 \%$ of the dry weight). More than half of the fruit total soluble sugars (TSS) was comprised of the seven carbon (C7) heptose sugar, D-mannoheptulose, and its polyol form, perseitol, with the balance being accounted for by the more common hexose sugars, glucose and fructose. Sugar content in the flesh tissues declined sharply as oil accumulation commenced. TSS declines in the seed were accompanied by a large accumulation of starch $\left(\approx 30 \%\right.$ of the dry weight). During postharvest storage at 1 or $5^{\circ} \mathrm{C}$, TSS in peel and flesh tissues declined slowly over the storage period. Substantial decreases in TSS, and especially in the C7 sugars, was observed in peel and flesh tissues during fruit ripening. These results suggest that the $\mathrm{C} 7$ sugars play an important role, not only in metabolic processes associated with fruit development, but also in respiratory processes associated with postharvest physiology and fruit ripening.
\end{abstract}

The avocado (Persea americana) fruit is characterized by its nutritious flesh, which contains an exceptionally high unsaturated oil content (up to $20 \%$ to $30 \%$, fresh weight), and its single large seed (Biale and Young, 1971; Davenport and Ellis, 1959; Whiley and Schaffer, 1994; Wolstenholme, 1986). Both the high oil content and the large seed require a high energy input during fruit growth and development, which must be provided by carbohydrates derived from photosynthesis (Wolstenholme, 1986). Carbohydrate storage and use processes in fruit tissues are therefore important aspects of fruit development and growth (Oliveira and Priestley, 1988).

Previous work (Appleman and Noda, 1941; Davenport and Ellis, 1959) has shown that a decrease in reducing sugar concentration during fruit growth is accompanied by an increase in oil concentration in the flesh of 'Fuerte' avocado. Similarly, Lee et al. (1983) showed that flesh dry weight accumulation was strongly correlated with oil accumulation, to the extent that dry weight is now used as a standard for measuring fruit maturity in California (Ranney et al., 1992). Despite the obvious importance of carbohydrate metabolism in avocado fruit development, little is known concerning its seasonal patterns of carbohydrate accumulation and use during fruit ontogeny. In addition, Liu et al. (1999) reported recently that the avocado tree is unique in its sugar composition. Large amounts of carbon 7 (C7) sugars Dmannoheptulose and its reduced form polyol, perseitol, were found in avocado leaves, shoots, trunk, and roots. The C7 sugars were found in equal or greater concentration to that of starch (Liu et al., 1999), a recognized major form of carbohydrate reserve for avocado (Olivera and Priestley, 1988; Scholefield et al., 1985). These two C7 sugars may also play an important role in avocado fruit development and growth.

Reserve carbohydrates are an energy source for the respiratory processes during fruit storage and ripening (Kozlowski, 1992).

\footnotetext{
Received for publication 13 Nov. 1998. Accepted for publication 9 Aug. 1999. This project was funded, in part, by a grant-in-aid from the California Avocado Commission. We wish to thank W. Manor and B. Patil for assistance in sample preparation. The cost of publishing this paper was defrayed in part by the payment of page charges. Under postal regulations, this paper therefore must be hereby marked advertisement solely to indicate this fact.

${ }^{1}$ Current address: Abbott Laboratories, 508 Miller Street, Wenatchee, WA 98801.

${ }^{2}$ To whom reprints request should be addressed.
}

The avocado fruit is characterized by a high respiration rate throughout growth and also during postharvest ripening (Blanke and Whiley, 1995; Bower and Cutting, 1988; Whiley et al., 1992). However, little is known concerning the nature of the carbon substrates which support respiratory processes. Varying storage temperatures and durations may result in different changes in carbohydrate storage and use and affect fruit quality (Eaks, 1990; Kikuta and Erickson, 1968; Luza et al., 1990; Spalding, 1976). The aim of the present study was therefore to quantify changes in major nonstructural carbohydrates (individual soluble sugars and starch) which occur during important developmental stages, and also during storage and ripening, in 'Hass' avocado fruit.

\section{Materials and Methods}

Plant material. The experimental site was at the University of California South Coast Research and Extension Center, Irvine, Calif. Mature 'Hass' trees on 'Duke 7' rootstock planted in 1986 at a $6.1 \times 6.1 \mathrm{~m}$ spacing ( 269 trees/ha) were used. The soil type is Yolo fine sandy loam with an average depth $>18 \mathrm{~m}$. One drip emitter $(15.1$ $\mathrm{L} \cdot \mathrm{h}^{-1}$ ) was placed at the base of each tree. Two years after planting, the drip emitter was replaced with a single low volume minisprinkler $\left(45.5 \mathrm{~L} \cdot \mathrm{h}^{-1}\right)$ placed at the base of each tree. Trees were irrigated as needed using the reference evapotranspiration from the California Irrigation Management Information System (CIMIS) as a guideline (Snyder et al., 1985). Standard fertilization practices for California were maintained (Goodall et al., 1981). Samples for leaf mineral nutrient analysis were collected annually and fertilization adjusted so that leaf nutrient levels remained within the recommended guidelines (Goodall et al., 1981). Yield and tree size were recorded annually (Tree size was estimated by an empirical formula: $0.131 \mathrm{H}(\mathrm{W} 1+\mathrm{W} 2)^{2}$, where $\mathrm{H}$ is tree height and $\mathrm{W} 1$ and $\mathrm{W} 2$ are the two perpendicular tree crown widths).

CARBOHYDRATE SAMPLING. Five blocks were randomly established among five rows of trees. Each block contained four to five adjacent trees as a sampling unit. Fruit in the blocks were tagged in May 1995 after peak fruit set. Monthly sampling began June 1995 when the fruit size measured $\approx 20 \times 30 \mathrm{~mm}$ and weighed $\approx 8$ g. Sampling continued to June 1996 which is considered the middle to the end of the commercial 'Hass' season for the 
growing area. Two fruit on two trees were taken between 1330 to 1430 HR from each block and analyzed separately as two replicates. In the first two sampling times, four fruit were taken from the different trees of each block and two were combined as one of the replicates due to small fruit size. The sampled fruit were stored in a thermal insulated chest with dry ice during transit to the University of California, Riverside campus $(65 \mathrm{~km})$ and stored temporarily at $4{ }^{\circ} \mathrm{C}$ upon their arrival. The samples were processed within $12 \mathrm{~h}$.

For the storage and ripening trial, fruit were harvested from the five blocks in late March 1996 during the commercial harvest season in early morning and transported to the F.G. Mitchell Postharvest Laboratory at the University of California, Kearney Agricultural Center (380 km distance), Parlier, Calif. The fruit were placed in their respective holding treatments by $1800 \mathrm{HR}$ and stored either at 1 or $5{ }^{\circ} \mathrm{C}(85 \%$ to $90 \%$ relative humidity (RH)) for 0,3 , or 6 weeks. One fruit from every block was used at each sampling time for a storage treatment. Fruit were ripened at $20^{\circ} \mathrm{C}$ ( $85 \%$ to $90 \% \mathrm{RH}$ ).

Fruit fresh weight, width, and length were recorded. A longitudinal slice, weighing $\approx 12 \mathrm{~g}$, was taken and separated into peel, flesh, and seed plus seedcoat. The separated tissue was weighed immediately and cut into small pieces and freeze dried for $\approx 50 \mathrm{~h}$ at -50 to $-51{ }^{\circ} \mathrm{C}$ (Freeze Dry System/Freezone 4.5, Labconco, Kansas City, Mo.). The freeze-dried samples from storage and ripening were transported to the University of California Riverside, campus (350 km distance) for further preparation and analysis. The dried tissue was weighed and ground using a Wiley mill to pass through a 40-mesh $(0.635-\mathrm{mm})$ screen.

Chemicals. D-mannoheptulose and perseitol were obtained from Pfanstiel (Waukegon, Ill.). All other chemicals were purchased from Sigma Biochemicals (St. Louis, Mo.).

Soluble SugAR ASSAY. Ground dried tissue $(0.1 \mathrm{~g})$ was added to $4 \mathrm{~mL} 80 \%$ ethanol and incubated in a $80{ }^{\circ} \mathrm{C}$ water bath for 30 min to extract the soluble sugars. The extract was centrifuged for $5 \mathrm{~min}$ at $4200 g_{\mathrm{n}}$ using a 5403 Centrifuge (Eppendorf, Hamburg, Germany) to pellet the tissue, the ethanol was decanted, and the tissues were reextracted three more times as above. A 6-mL portion of the pooled ethanol extract was then taken to dryness in a Speed Vac Concentrator (SAVANT, Farmingdale, N.Y.). The dried samples were resuspended in $1 \mathrm{~mL}$ deionized water and deionized using $1 \mathrm{~mL}$ anion and cation resin columns (AG1-X8/ formate and AG50W-X8/ $\mathrm{H}^{+}$, BIO-RAD, Hercules, Calif.). Sugars were eluted with $15 \mathrm{~mL}$ water and $5 \mathrm{~mL}$ was taken to dryness as above. The sugars were then redissolved in 300 to $400 \mu \mathrm{L}$ water, filtered $(0.45 \mu \mathrm{m}$ pore size $)$ and then $20 \mathrm{~mL}$ was analyzed by HPLC using a Sugar-pak (Waters, Milford, Mass.) column. The separated sugars were detected using a 156 Refractive Index Detector (Altex, Fullerton, Calif.) with a 4290 data integrator (Varian, Sugarland, Texas) and quantified by comparison to known sugar standards.

STARCH ASSAY. The assay was based on procedures described by Madore (1990) and Hendrix (1993). The extracted residues were oven dried at $55^{\circ} \mathrm{C}$ and suspended in $2.0 \mathrm{~mL} 2 \mathrm{~N} \mathrm{KOH}$ and incubated in a boiling water bath for $1 \mathrm{~h}$ to gelatinize the starch. After cooling, $2.0 \mathrm{~mL} 2 \mathrm{~N}$ acetic acid was added to the samples to adjust the $\mathrm{pH}$ to 4.5 . The starch was then hydrolyzed to glucose using amyloglucosidase (146 units for each sample in a total volume of $7 \mathrm{~mL}$ ) (Fluka, Ronkonkoma, N.Y.). The glucose content was assayed using a commercially available kit (Sigma HK20) and quantified by comparison to a known glucose standard using a 3550-UV Microplate Reader (BIO-RAD) at $340 \mathrm{~nm}$.
The final carbohydrate concentrations are presented as the percent of sugar or starch of the dry tissue.

Statistical ANALYsis. Differences in sugar and starch reserves following different storage conditions in ripening and ripened fruits were tested using Means/SLD multicomparison method by SAS GLM procedures (SAS Inst., Inc., 1987).

\section{Results}

Developmental Changes. Fruit growth from the June to September growth phase was characterized by a rapid size increase from $22 \mathrm{~mm}(\mathrm{w}) \times 29 \mathrm{~mm}$ (l) to $60 \mathrm{~mm}$ (w) $\times 83 \mathrm{~mm}$ (l) (Fig. 1A). Concomitant with the rapid expansion in fruit size was a rapid increase in fruit biomass (Fig. 1B). Water content remained relatively constant at $\approx 85 \%$ (Fig. 1C) until September, after which the increase in fruit weight slowed and fruit water content declined slowly (Fig. 1B and C). Fruits continued to expand in size until December (Fig. 1A).

From June through September, peel, flesh, and seed tissue dry weights increased corresponding to fruit growth (Fig. 2A-C). Once the fruit passed this rapid expansion phase, the peel tissue maximum dry weight ( $\approx 6 \mathrm{~g}$; Fig. $2 \mathrm{~A}$ ) was achieved. The seed reached maximum dry weight of $\approx 13 \mathrm{~g}$ (Fig. 2C) near December. This coincided with the slowing of overall fruit growth. The flesh tissue reached a minimum maturity of $20.8 \%$ dry weight (Ranney et al., 1992) near mid-October (Fig. 2B). Unlike the peel and seed

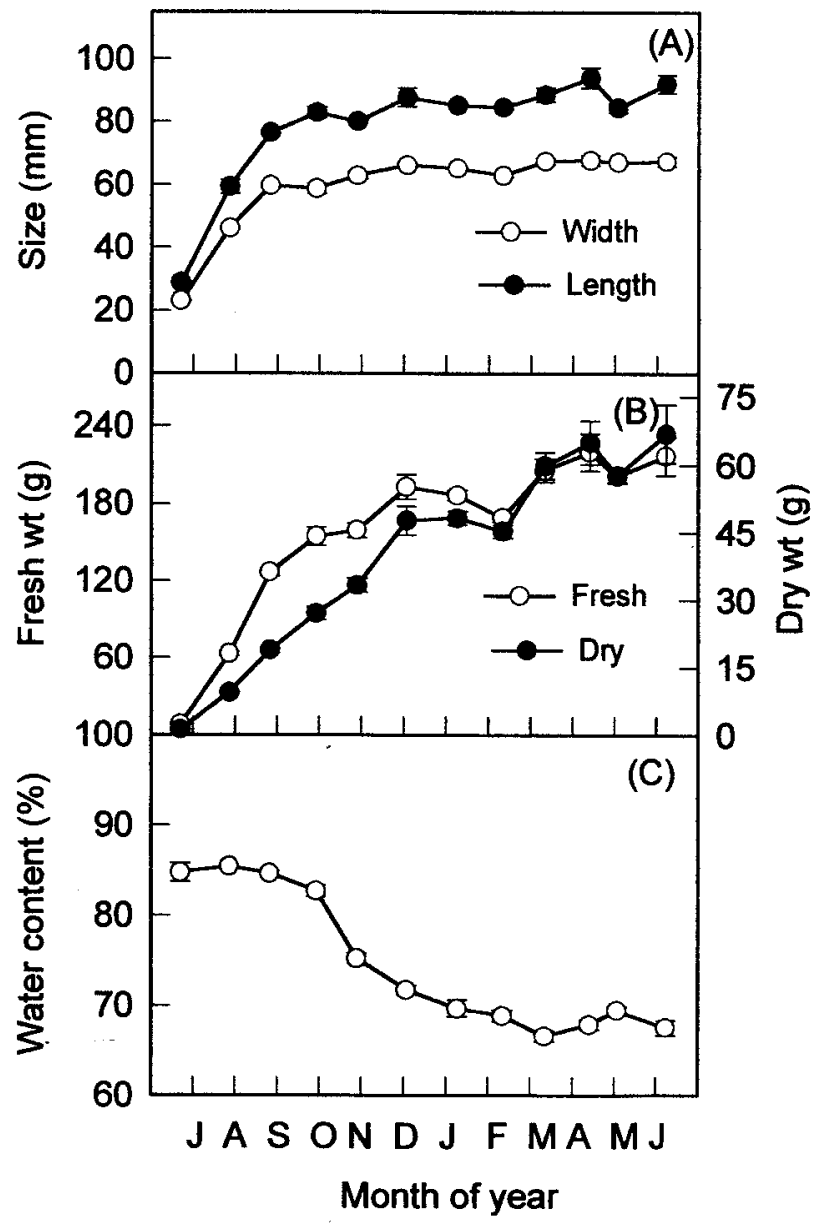

Fig. 1. Seasonal changes in (A) fruit size, (B) total mass, and (C) water content (flesh with peel) of 'Hass' avocado on 'Duke 7' rootstock. Vertical bars represent \pm 1 SE. 


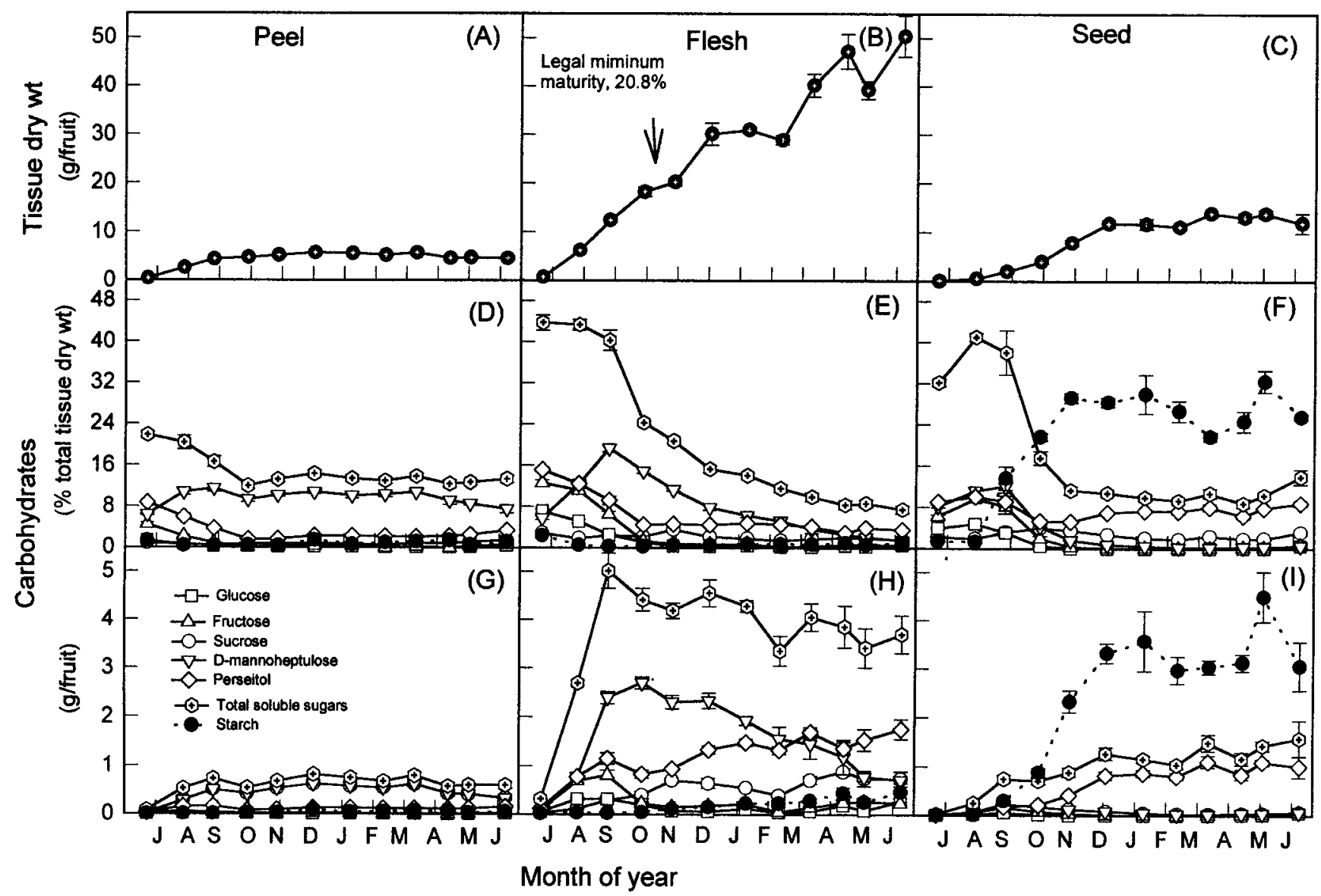

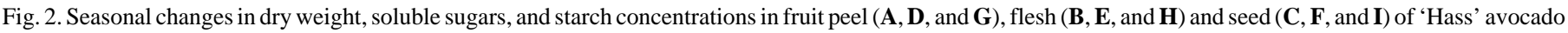
on'Duke 7' rootstock. Vertical bars represent \pm 1 SE.

tissues, however, the dry weight of the flesh tissue continued to increase at about the same rate throughout the sampling period (Fig. 2B). The flesh tissues accounted for over $60 \%$ of the total fruit dry weight.

High total soluble sugar (TSS) concentrations, especially during early fruit growth, were observed in the peel, flesh and seed tissues (Fig. 2D-F). In June, 2 months after fruit set, soluble sugars comprised $\approx 22 \%$ of the peel, $44 \%$ of the flesh and $32 \%$ of the seed dry weight (Fig. 2D-F). As the fruit grew and rapidly gained weight (Fig. 2B), the flesh tissue accumulated proportionally higher levels of TSS (Fig. 2E). During this time, flesh TSS increased sharply to $\approx 5 \mathrm{~g}$ coinciding with the increase in dry weight (Fig. 2B and H). Following the period of rapid fruit growth (August to late October), however, the flesh tissue TSS concentration decreased to $\approx 20 \%$ (Fig. $2 \mathrm{E}$ ). As the fruit continued to grow, the decrease in flesh tissue TSS slowed gradually (Fig. 2E and $\mathrm{H}$ ). In the peel, TSS concentration gradually decreased to around $12 \%$ of the dry weight by the end of the rapid fruit growth phase (Fig. 2D). There was little subsequent change in peel TSS concentration, and its accumulated sugar amount $(\approx 1 \mathrm{~g})$ during subsequent fruit growth and development (Fig. 2D and G).

Seed TSS concentration increased sharply from $32 \%$ to $41 \%$ of the dry weight during June to August and then declined during the rapid expansion period (Fig. 2F). On a per fruit basis, however, seed TSS concentration and dry weight remained relatively constant (Fig. 2C, F, and I).

Five soluble sugars were detected in the avocado fruit: the disaccharide sucrose, and its component hexoses, fructose and glucose, and also the seven carbon (C7) reducing sugar, Dmannoheptulose, and its reduced polyol form, perseitol (Fig. 2DI). Together, these five sugars constituted at least $98 \%$ of the fruit TSS. Trace amounts of higher molecular weight oligosaccharides were detected in some fruit samples, especially in young fruit (data not shown).

The seasonal patterns observed in TSS in the peel, flesh, and seed tissues were mainly due to seasonal fluctuations in fructose, glucose, D-mannoheptulose, and perseitol (Fig. 2D-I). Sucrose concentrations were consistently low in all sampled tissues and fluctuated very little (Fig. 2D-F). In very young fruitlets (June) the predominant sugars in all fruit tissues were glucose, fructose, D-mannoheptulose, and perseitol (Fig. 2D-F). As the fruit finished the rapid expansion phase, fructose and glucose had decreased to very low concentrations (Fig. 2D-F).

The most abundant and persistent sugars in a avocado fruit were the $\mathrm{C} 7$ sugars. During early fruit growth, the $\mathrm{C} 7$ sugars were the dominant sugars. D-mannoheptulose accounted for $12 \%$, $19 \%$, and $12 \%$, of the TSS in the peel, flesh, and seed, respectively (Fig. 2D-F). Perseitol accounted for 9\%, 15\%, and $10 \%$ of the TSS in the peel, flesh, and seed, respectively (Fig. 2D-F). As the fruit passed the rapid expansion phase, D-mannoheptulose concentrations decreased in the flesh and seed (Fig. 2E, F, H, and I) but remained high in the peel (Fig. 2D and G). Perseitol concentrations decreased in the peel and flesh (Fig. 2D and E). As the fruit matured, perseitol concentrations varied little and were $\approx 3 \%, 4 \%$, and $8 \%$ of the dry weight, in the peel, flesh, and seed tissues, respectively at full maturity. The total amount of perseitol 


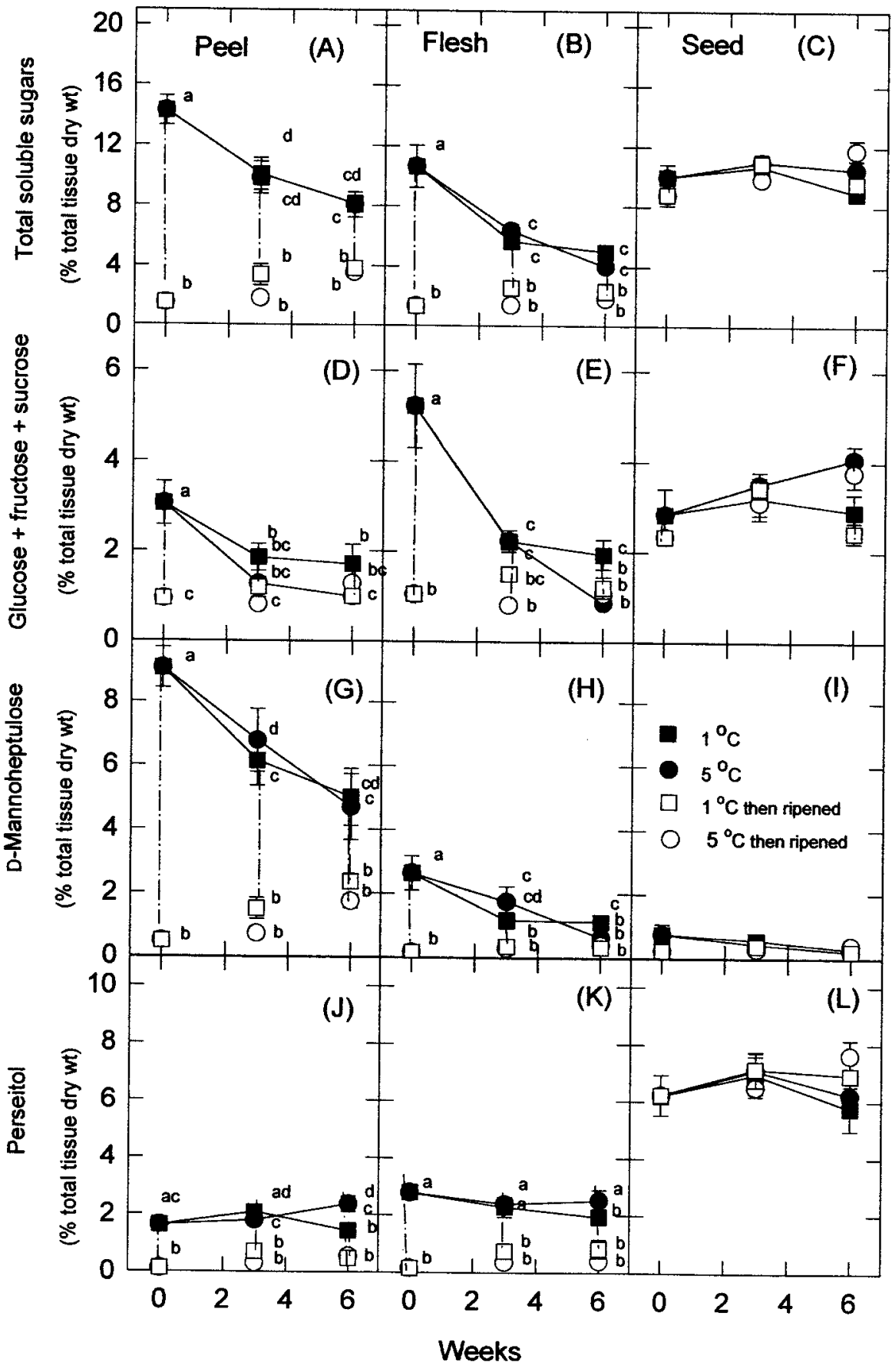

Postharvest Changes. Significant $(P \leq 0.05)$ differences in the reserve sugar levels in the peel and flesh were found between the fruit due to storage treatments and following ripening (Fig. $3)$. Following either 3 or 6 weeks storage $\left(1,5^{\circ} \mathrm{C}\right)$, the peel and flesh tissue had significantly $(P \leq 0.05)$ lower TSS than that of the control (unripe, no storage; Fig. 3A and B). Although there was a general trend towards lower TSS concentrations in unripe fruit peel and flesh with increasing storage duration, a significant $(P \leq 0.05)$ difference was found only in the peel of fruit stored for 3 and 6 weeks at $1{ }^{\circ} \mathrm{C}$ (Fig. 3A and B). Fruit that were stored either at 1 or $5{ }^{\circ} \mathrm{C}$ had the same peel and flesh TSS concentrations $(P>0.05)$. Once the fruit ripened, the peel and flesh TSS levels decreased dramatically regardless of storage temperature or duration $(P \leq 0.05)$ (Fig. 3A and $B$ ). The unripe fruit without storage (control) had $\approx 14 \%$ and $10 \%$ (based on dry weight) of TSS concentrations in the peel and flesh, respectively (Fig. 3A and $\mathrm{B}$ ). There was about a $5 \%$ reduction in the peel and flesh TSS when the control fruit were compared to the unripe stored fruit. When the control fruit were ripened at $20{ }^{\circ} \mathrm{C}$, there was a decrease of $10 \%$ and $8 \%$ in the peel and flesh TSS concentrations, respectively (Fig. 3A and B).

The decrease in the TSS concentrations of the flesh and peel with low temperature storage resulted from the significant $(P \leq 0.05)$ reduction in glucose, fructose, sucrose (Fig. 3D and E) and the $\mathrm{C} 7$ sugar, D-mannoheptulose (Fig. 3G and H). Peel and flesh perseitol concentrations changed little during storage but dropped significantly $(P \leq$ $0.05)$ to near zero as the fruit ripened (Fig. 3J and K). During fruit ripening, a dramatic decrease was also observed in the concentrations of glucose, fructose,

Fig. 3. Changes in soluble sugar concentrations in fruit peel $(\mathbf{A}, \mathbf{D}, \mathbf{G}$, and $\mathbf{J})$, flesh $(\mathbf{B}, \mathbf{E}, \mathbf{H}$, and $\mathbf{K})$ and seed $(\mathbf{C}, \mathbf{F}, \mathbf{I}$, and $\mathbf{L})$ of 'Hass' avocado on 'Duke 7' rootstock during 1 or $5^{\circ} \mathrm{C}$ storage (closed symbols) and after ripening at $20^{\circ} \mathrm{C}$ (open symbols). Vertical bars represent \pm 1 SE. Lower case letters near the symbols indicate significant differences $(P \leq 0.05)$ among the storage treatments and ripening status. The absence of letters indicates no significant differences.

increased slightly in the flesh and seed throughout fruit growth and maturation (Fig. 2H and I).

The peel and flesh accumulated very little ( $<1 \%$ in most cases) starch (Fig. 2D, E, G and H). The seed starch concentration remained low $(<1 \%$ of the dry weight), and unchanged during the early stages of fruit development (Fig. 2F). As the seed weight started to increase rapidly, starch accumulated in the seed and accounted for nearly $30 \%$ of the dry weight from November (Fig. 2F). sucrose and D-mannoheptulose in the peel and flesh of either stored or nonstored fruit (Fig. 3D, E, G, and H). The decreases in those individual sugars resulted in the decrease in TSS of the peel and flesh during fruit ripening (Fig. 3D, E, G, H, J, and K). Generally, no significant $(P>0.05)$ difference in TSS concentrations due to storage temperature, duration or ripening were found in the seed (Fig. 3C, F, I, and L). Similar to the control, the peel and flesh of the fruit following storage, regardless of the stage of ripeness had very low levels of starch $(0.3 \%$ to $1.3 \%$; Fig. $4 \mathrm{~A}$ and B). The seed starch level was significantly lower $(P \leq 0.05)$ for fruit that were stored at 1 or $5^{\circ} \mathrm{C}$ for either 3 or 6 weeks than for the control or fruit ripened without storage (Fig. 4C). No significant $(P>0.05)$ differences in the seed starch concentration was observed between unripe and ripened fruit within the same storage condition. 


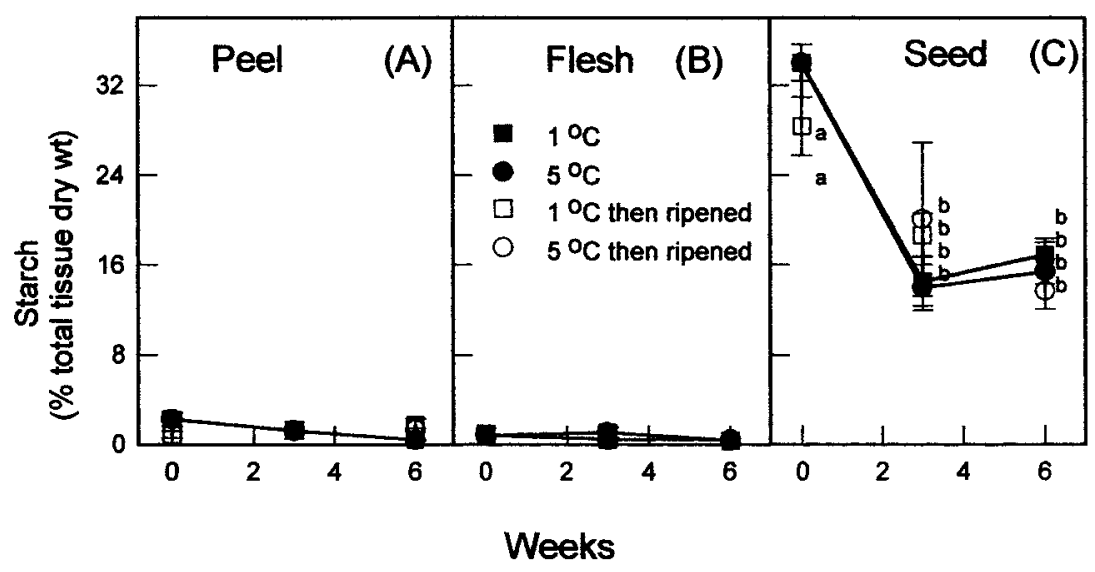

Fig. 4. Changes in starch concentrations in fruit (A) peel, (B) flesh, and (C) seed of 'Hass' avocado on 'Duke 7' rootstock during 1 or $5^{\circ} \mathrm{C}$ storage and ripening at $20{ }^{\circ} \mathrm{C}$. Vertical bars represent \pm 1 SE. Lower case letters near the symbols indicate significant differences $(P \leq 0.05)$ among the storage treatments and ripening status. The absence of letters indicates no significant differences.

\section{Discussion}

The seasonal pattern of 'Hass' avocado fruit growth and development reported herein was similar to that observed by Eaks (1990), Inoue and Takahashi (1990), and Kikuta and Erickson (1968) for 'Hass' and other avocado cultivars. The C7 sugars, Dmannoheptulose and perseitol, were the major nonstructural carbohydrates present in avocado fruit tissues throughout the study and as such appear to play an essential role in fruit growth. TSS are a major biomass component for the young fruit during the early rapid development stage (Fig. 2). Specifically early fruit growth appears to depend on the accumulation of fructose, glucose, D-mannoheptulose, and perseitol reserves. This high tissue TSS concentration may be important in allowing the reduction of cellular water potential to enhance cell water uptake, resulting in the observed high water content of the young fruit. The young fruit undergoes rapid expansion growth, which is controlled primarily by turgor pressure changes and thus depends on its water status (Schroeder and Wieland, 1956; Whiley and Schaffer, 1994).

The avocado peel and flesh tissues are capable of fixing $\mathrm{CO}_{2}$ but their net assimilation rate is negative due to a very high fruit respiration rate throughout growth (Blanke and Whiley, 1995; Whiley et al., 1992). Dry matter accumulation during fruit growth must therefore rely strongly on carbon delivered from source tissues (leaves and storage reserves such as stem tissues) via phloem transport. The nature of the transported form of carbon in avocado is unknown. However, as avocado fruit contains a sugar alcohol, perseitol, in significant amounts, it is highly likely that this seven carbon sugar serves as a phloem transport sugar. This would represent a similar physiological strategy to that of other fruit tree crops such as apple [Malus sylvestris L. Mill. var. domestica (Borkh.) Mansf], peach [Prunuspersica (L.)Batsch (Peach Group)] and related species (Loescher and Everard, 1996; Sakai, 1966) and olive (Olea europaea L.) (Flora and Madore, 1993), which translocate polyol forms of common hexose (C6) sugars.

At about the minimum maturity stage (20.8\% dry weight for 'Hass' avocado; Fig. 1B), TSS no longer accumulated in fruit tissues. At this point, the flesh begins to accumulate oil (Eaks, 1990; Lee et al., 1983; Liu et al., unpublished; Ranney et al., 1992), and this may explain why cessation of sugar accumulation was seen in the flesh (Fig. 2H). Imported sugars are most likely used for lipid synthesis in the flesh, and also for starch accumulation which is observed in the seed (Fig. 2I). In the later stages of fruit growth, a carbon balance appears to be maintained in the peel and seed as indicated by the small changes in their dry weight and amounts of nonstructural carbohydrate (Fig. 2A, C, G, and I).

In general, the increase in avocado fruit biomass follows its growth curve and appears to have two physiological carbon accumulation and use phases. In the first phase, soluble sugars are the major source of carbon for the increase in biomass. The fruit is a strong reproductive sink and stores photoassimilates (Cannell and Dewar, 1994) during the early developmental stage after fruit set. With the slowing of fruit growth, the second phase occurs. This coincides with cessation of TSS accumulation and the gradual decrease in the amount of accumulated sugars (Fig. 2H). This can also be correlated with the accumulation of oil.

During low temperature storage there is little change in amount or composition of the lipid that accumulates in the fruit flesh in the latter stages of development changes (Davenport and Ellis, 1959; Eaks, 1990; Luza et al., 1990). The significant decrease in the common sugars (sucrose, fructose, and glucose) and Dmannoheptulose in the peel and flesh during postharvest storage at either 1 or $5{ }^{\circ} \mathrm{C}$, strongly suggests that those stored sugars contribute to the carbon energy source used by the respiratory process. During low temperature storage, the seed preferably uses the stored starch available (Fig. 4C).

During fruit ripening all sugars stored in the peel and flesh were consumed, whereas the carbohydrate reserves in the seed remained intact. This suggests that the energy source stored in the seed was separate from that used for respiration during fruit ripening. Little change in perseitol concentration was observed during low temperature storage. However, after fruit ripening a significant decrease in peel and flesh perseitol concentrations was seen. This implies that more respiratory carbon is required by the fruit ripening process than by low temperature storage, and can be explained by the climacteric behavior of the fruit, which is marked by a rise in respiration during ripening.

The decrease in C7 sugar concentrations in the peel and flesh after low temperature storage and after ripening suggest further that the avocado fruit has an enzymatic mechanism to metabolize C7 sugars. In avocado, our study would suggest that the $\mathrm{C} 7$ sugars act as translocated forms of carbon, storage reserves, and respiratory metabolites. Avocado fruit do not ripen on the tree (Bower and Cutting, 1988), and it is possible that a reduction in sugar levels is a physiological prerequisite for fruit ripening. Only when the fruit are removed from the tree and the supply of sugars from source shoots depleted, was the ripening process initiated. The $\mathrm{C} 7$ sugars, D-mannoheptulose and perseitol, may therefore play a major role in the control of this sugar-related ripening. In this context, it is very intriguing that D-mannoheptulose is a potent inhibitor of the glycolytic respiratory process (Board et al., 1995).

\section{Literature Cited}

Appleman, D. and L. Noda. 1941. Biochemical studies of the Fuerte avocado fruit—A preliminary report. Calif. Avocado Soc. Yrbk. 26:60-63.

Biale, J.B. and R.E. Young. 1971. The avocado pear, p. 1-63. In: A.C. Hulme (ed.). The biochemistry of fruits and their products. vol. 2. 
Academic Press, London.

Blanke, M. and A.W. Whiley. 1995. Bioenergetics, respiration cost and water relations of developing avocado fruit. J. Plant Physiol. 145:8792.

Board, M., A. Colquhoun, and E.A. Newsholme. 1995. High Km glucose-phosphorylating (glucokinase) activities in a range of tumor cell lines and inhibition rates of tumor growth by the specific enzyme inhibitor mannoheptulose. Cancer Res. 55:3278-3285.

Bower, J.P. and J.G. Cutting. 1988. Avocado fruit development and ripening physiology. Hort. Rev. 10:229-271.

Cannell, M.G.R. and R.C. Dewar. 1994. Carbon allocation in trees: A review of concepts for modeling, p. 59-104. In: M. Begon and A.H. Fitter (eds.). Advances in ecological research. vol. 25. Academic Press, London.

Davenport, J.B. and S.C. Ellis. 1959. Chemical changes during growth and storage of the avocado fruit. Austral. J. Biol. Sci. 12:445-454.

Eaks, I.L. 1990. Change in the fatty acid composition of avocado fruit during ontogeny, cold storage and ripening. Acta Hort. 269:141-152.

Flora, L.L. and M.A. Madore. 1993. Stachyose and mannitol transport in olive (Olea europaea L.). Planta 189:484-490.

Goodall, G.E., T.W. Embleton, and R.G. Platt. 1981. Avocado fertilization. Univ. Calif. Div. Agr. Sci. (Oakland) Lflt. 2024.

Hendrix, D.L. 1993. Rapid extraction and analysis of non-structural carbohydrates in plant tissues. Crop Sci. 33:1306-1311.

Inoue, H. and B. Takahashi. 1990. Studies on the bearing behavior and yield composition of the avocado tree. J. Jpn. Soc. Hort. Sci. 59:487501.

Kikuta, Y. and L.C. Erickson. 1968. Seasonal changes of avocado lipids during development and storage. Calif. Avocado Soc. Yrbk. 52:102108.

Kozlowski, T.T. 1992. Carbohydrate sources and sinks in woody plants. Bot. Rev. 58:107-222.

Lee, S.K., R.E. Young, P.M. Schifman, and C.W. Coggins, Jr. 1983. Maturity studies of avocado fruit based on picking dates and dry weight. J. Amer. Soc. Hort. Sci. 108:390-394.

Liu, X., P.N. Robinson, M.A. Madore, G.W. Witney, and M.L. Arpaia. 1999. 'Hass' avocado carbohydrate fluctuations. I. Growth phenology. J. Amer. Soc. Hort. Sci. 124(6):671-675.

Loescher, W.H. and J.D. Everard. 1996. Sugar alcohol metabolism in sinks and sources, p. 185-207. In: E. Zamski and A.A. Schaffer (eds.).
Photoassimilate distribution in plants and crops, source-sink relationships. Marcel Dekker, New York.

Luza, J.G., L.A. Lizana, and L. Masson. 1990. Comparative lipids evolution during cold storage of three avocado cultivars. Acta Hort. 269:153-160.

Madore, M. A. 1990. Carbohydrate metabolism in photosynthetic and nonphotosynthetic tissues of variegated leaves of Coleus blumei Benth. Plant Physiol. 93:617-622.

Oliveira, C.M. and C.A. Priestley. 1988. Carbohydrate reserves in deciduous fruit trees. Hort. Rev. 10:403-430.

Ranney, C.A., G. Gillette, A. Brydon, S. Mclntyre, O. Rivers, C.A. Vasquez, and E. Wilson. 1992. Physiological maturity and percent dry matter of California avocado, p. 379-385. In: C.J. Lovatt (ed.). Proc. 2nd World Avocado Congr. Orange, Calif., April 1991.

Sakai, A. 1966. Seasonal variations in the amounts of polyhydric alcohol and sugar in fruit trees. J. Hort. Sci. 41:207-213.

SAS Institute, Inc. 1987. Proprietary software release 6.04. SAS Inst., Cary, N.C.

Scholefield, P.B., M. Sedgley, and D.McE. Alexander. 1985. Carbohydrate cycling in relation to shoot growth, floral initiation and development and yield in the avocado. Scientia Hort. 25:99-110.

Schroeder, C.A. and P.A. Wieland. 1956. Diurnal fluctuation in size in various parts of the avocado tree and fruit. Proc. Amer. Soc. Hort. Sci. 68:253-258.

Snyder, R., D.W. Henderson, W.O. Pruitt, and A. Dong. 1985. California irrigation management information system. Final report: land, air, and water resources papers 10013 A, B, C. Dept. Land, Air, and Water Resources, Univ. Calif., Davis, Calif.

Spalding, D.H. 1976. Storage of avocados, p. 109-113. In: J.W. Sauls, R.L. Phillip and L.K. Jackson (eds.). Proc. 1st Intl. tropical fruit short course: The avocado. Univ. Fla. Press, Gainesville.

Whiley, A.W. and B. Schaffer. 1994. Avocado, p. 1-35. In: B. Schaffer and P.C. Andersen (eds.). CRC handbook of environmental physiology of fruit crops. vol. 2. Subtropical and tropical crops. CRC Press, Boca Raton, Fla.

Whiley, A.W., B. Schaffer, and S.P. Lara. 1992. Carbon dioxide exchange of developing avocado (Persea americana Mill.) fruit. Tree Physiol. 11:85-94.

Wolstenholme, B.N. 1986. Energy costs of fruiting as a yield-limiting factor with special reference to avocado. Acta Hort. 175:121-126. 